or bacteria, we need more diagnostic data, for the method of combating the disease must necessarily depend on the nature of the micro-organism to be combated. David Ellis.

Royal Technical College, Glasgow, March zo.

THE object of the article on bee disease which appeared in NATURE of March 2I was to emphasise the fact that, though bees suffer from many diseases, the macroscopic symptoms are practically the same and to claim that the only acceptable definition of "Isle of Wight disease" is the "disease caused by Nosema apis." As Mr. EHlis's experience would appear to support this contention, it is to be regretted that he should have received the impression that Nosema, when found, has no causal connection with the disease. The correct deduction would appear to be that, in spite of the guarantee of the professional lecturer on bee-keeping, the bees he examined were not suffering from "Isle of Wight disease." It would at any rate be interesting to know on what scientific data this guarantee was given. The' conclusions in the last sentence of $\mathrm{Mr}$. Ellis ${ }^{\circ}$. communication are identical with those drawn in my article.

The Writer of the Article.

Prices of Scientific Annaratus.

THE method of advertising at present adopted by some of our scientific instrument makers is, I venture to think, open to serious objection. The prices.mentioned are, it would appear, not the current prices at all. An addendum (printed in small type or in some other inconspicuous way) informs the public that, owing to the war, the prices quoted in the advertisement are subject to an addition of ro or 20 per cent., and in some cases to as much as 33 per cent. Would it not be advisable to abandon entirely the publication of pre-war prices, and to quote instead the sums for which the various forms of apparatus are to be obtained at the time the advertisement meets the public eye?

Fredk. J. Brodie.

Loxley Road, Wandsworth Common, S.W., April 2.

\section{COTTON-GROWING STATISTICS.}

THE forecasting of the cotton crop, upon whick depends one of the greatest industries of the world and in which Great Britain is especially interested, has settled into a mixture of reports based on a glance round a cotton field, a chat with a proprietor, and a combination of a few climatic notes which a Government department wisely issues for a farmer's guidance. It is all unsubstantial, but these reports are spread over the world and are used as a basis for business and speculation according to the credit any particular reporter may have at the moment.

It is not surprising that serious attempts are made to eliminate this casual methoo and establish a scientific basis in its stead. A short time ago a particular investigation conducted in Egypt necessitated the obtaining of a certain amount of data of the growth of the cotton plant. The collection of the data was carried out on scientific lines and evidently served its purpose. It was found, however, that the data and method used for this particular purpose gave indication that their use could be extended to the solution of a far more important problem, viz. forecasting with some degree of accuracy the flowering, ripening, and stages in the picking of the cotton crop. In other NO. 2528 , VOL. IOI? words, an estimate of the yield of the crop could be made several weeks before the cotton was ready for picking. The line of argument for this conclusion is fairly simple. The rate of the growth of the plant in height (stem growth) was considered to be, in some proportion, indicative of the rate of flowering; so that a curve of growth, compared with some standard growth curve, would indicate the rate of flowering three weeks before flowering commenced. The flowering curve, in its turn (with certain corrections), offered a ready means of estimating the number of bolls of cotton, or the amount of ripe cotton, that could be anticipated two months later. Forecasting on these lines became a scientific matter, and it held out a distinct promise of a wide field of usefulness.

The Ministry of Agriculture of Egypt evidently determined to test this new method of forecasting the cotton crop, and during the year I9I 5 arranged a number of stations in Egypt where the growth of various classes of the cotton plant could be observed systematically and complete data obtained of their rates of growth, flowering, and ripening of the bolls. The whole of the data thus collected has now been published in the A gricultural Journal of Egypt (vol. vii., I9I7). An elaborate series of curves has been graphed from the data. It is apparent that one of the chief objects of the whole investigation was the testing of the new method of forecasting, for a statement is made to that effect. In spite of this, however, no direct reference is afterwards made in the report as to the effectiveness of the method, nor has an attempt been made to express an opinion.

The curves and data accompanying them have evidently been considered by the Egyptian authorities to be so adverse to this new method of forecasting that they have deliberately refrained from editorial comment.

Whilst this particular feature occupies ninetenths of the report, it is evident from the other sections, in the form of editorial remarks and data, that previous to I9I 5 cottonyrowing in Egypt was not conducted on correct lines, and that too strict an adherence to Mendelian principles was not yielding the results anticipated. In the editorial statements on this feature the phraseology used is unfortunately liable to misconstruction. It must, however, be conceded that further remarks on this feature make it clear that whilst Mendelian principles will be the basis of future work (this, of course, is inevitable), consideration will be given to practical factors according to districts and local conditions.

The whole subject is one of such practical utility that someone should be associated with the botanist to act as a guide in pointing out the direction in which utility is desirable. One or two details of the report-for instance, the measurement of the fibres, etc., and the import of them, the experimental spinning, and the interpretation of the results-clearly indicate the necessity for complementing the staff of the Egyptian Ministry of Agriculture dealing with cotton-growing by the addition of a man thoroughly acquainted with all the practical aspects of the cotton industry. 